\title{
Post-marketing surveillance in the published medical and grey literature for percutaneous transluminal coronary angioplasty catheters: a systematic review
}

\author{
Julie Polisena ${ }^{1,2^{*}}$, Alan J Forster ${ }^{2,3,4,5,6}$, Karen Cimon ${ }^{1}$ and Danielle Rabb
}

\begin{abstract}
Background: Post-marketing surveillance (PMS) may identify rare serious incidents or adverse events due to the long-term use of a medical device, which was not captured in the pre-market process. Percutaneous transluminal coronary angioplasty (PTCA) is a non-surgical procedure that uses a balloon-tipped catheter to enlarge a narrowed artery. In 2011, 1,942 adverse event reports related to the use of PTCA catheters were submitted to the FDA by the manufacturers, an increase from the 883 reported in 2008. The primary research objective is to conduct a systematic review of the published and grey literature published between 2007 and 2012 for the frequency of incidents, adverse events and malfunctions associated with the use of PTCA catheters in patients with coronary artery disease (CAD). Grey literature has not been commercially published.

Methods: We searched MEDLINE, EMBASE, the Cochrane Central Register of Controlled Trials and PubMed for medical literature on PMS for PTCA catheters in patients with CAD published between January 2007 and July 2012. We also searched the grey literature.

Results: This review included 11 studies. The in-hospital adverse events reported were individual cases of myocardial infarction and hematoma. In studies of patients with coronary perforation, more patients with balloon angioplasty were identified compared with patients who required stenting.

Conclusions: Our systematic review illustrates that the volume and quality of PMS studies associated with the use of PTCA catheters in patients with CAD are low in the published and grey literature, and may not be useful sources of information for decisions on safety. In most studies, the objectives were not to monitor the long-term safety of the use of PTCA catheters in clinical practice. Future studies can explore the strengths and limitations of PMS databases administered by regulatory authorities.
\end{abstract}

Keywords: Post-marketing surveillance, Medical device, Incident, Adverse event, Malfunction

\section{Background}

The US Food and Drug Administration (FDA) defines a medical device as an instrument used to diagnose, treat or prevent a disease or abnormal physical condition without any chemical action in the body [1]. The medical device industry has grown in the past ten years.

\footnotetext{
* Correspondence: juliep@cadth.ca

${ }^{1}$ Canadian Agency for Drugs and Technologies in Health, Ottawa, 600-865 Carling Ave K1S 5S8, Ontario, Canada

${ }^{2}$ Department of Epidemiology and Community Medicine and Epidemiology, University of Ottawa, Ottawa, Ontario, Canada

Full list of author information is available at the end of the article
}

Between 2004 and 2009, the sales of medical devices increased by $56 \%$, while pharmaceutical sales increased by $38 \%$ during the same period [2]. Excluding diagnostics, the medical device industry is a USD 200 billion business worldwide, with projected sales of USD 95 billion in 2010 in the US alone [2].

Unlike drug therapies, the approval processes for medical devices typically do not require clinical effectiveness and safety data derived from a randomized clinical trial (RCT) [3], even for FDA class III medical devices, which have the highest risk for patients. Manufacturers must

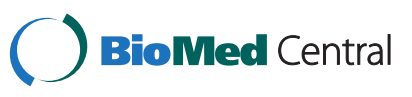


perform studies on human subjects, but there are no standards for sample size, design or follow-up period, as there are for medications $[4,5]$. Thousands of medical device applications are submitted each year in the US. However, fewer than 100 were considered to be high-risk devices and went through a pre-market approval (PMA) process. Instead, most applications undergo a $510(\mathrm{k})$, a pre-market submission required by the FDA, where manufacturers claim that their device is as safe and effective as the comparator device available on the market. In these studies, measures of safety and effectiveness are not mandatory [3]. PMA is the strictest submission process and the FDA requires that the submission contains valid scientific evidence to ensure the safety and effectiveness of the medical device during its intended use [6]. Equivalent clinical evidence, therefore, would unlikely be available across all medical devices, rendering product comparisons nearly impossible [7].

Post-marketing surveillance (PMS) and epidemiology programs are complementary to the pre-market process since they may identify rare serious adverse events due to long-term use of the medical device not captured previously $[4,8]$. PMS collects data from the monitoring and assessment of adverse reactions to marketed health products, as well as standard market intervention and communication procedures, and associated policy development and business transformation activities [9]. Challenges associated with PMS studies include finding sources with relevant medical device data and identifying a patient population that had been exposed to a specific medical device [10]. It is possible that device-related adverse events are underreported since manufacturers are not usually obliged to search for device malfunctions actively [11]. Further, there may be a disincentive to report adverse events or device malfunctions if health-care providers use them in patient populations not originally approved by the regulatory authority $[11,12]$.

Given the above limitations in the regulatory requirements for monitoring the safety of medical devices, it is possible that there are significant deficiencies in their safety. While this might be true for all devices, we have decided to focus specifically on cardiovascular devices. The volume, complexity and costs of cardiovascular devices are on the rise $[11,12]$. For example, the prevalence of coronary artery disease (CAD) in 2005 was 16 million people in the US, and the estimated direct and indirect cost of CAD for 2008 was USD 156.4 billion [13]. Percutaneous transluminal coronary angioplasty (PTCA) is a non-surgical procedure, which uses a balloon-tipped catheter to enlarge a narrowed artery as an alternative to open-heart surgery [14]. The PTCA catheter was approved by the FDA in 1980. In 2010, the FDA reclassified standard PTCA catheters from class III to class II (that is, lower risk) when used for balloon dilation to treat narrowed or blocked arteries in patients with coronary ischemia. To date, 33 catheters made by 10 manufacturers have been approved, including two devices in 2010 and seven devices in 2011 [15].

In 2011, 1,942 adverse event reports related to the use of PTCA catheters were submitted to the FDA by the manufacturers, an increase from the 883 reported in 2008 [15]. It is unclear if the rise in the number of adverse event reports from 2008 to 2011 was related to reclassification of the device from a class III to II risk level (with a less stringent market approval process) or whether a greater number of PTCA catheters were implanted in patients with CAD during the time period. The patient outcomes for 1,662 adverse events reported in 2011 remain unknown. In 2008, 26 adverse event outcomes were reported versus 50 in 2011, and the most frequent device malfunction reported was material rupture. Between 2009 and 2010, there were two class 1 recalls of PTCAs, POWERSAIL ${ }^{\circledR}$ Coronary Dilation Catheters and AngioSculpt PTCA, due to device malfunctions that could lead to serious adverse events, including air embolism, myocardial infarction (MI) and death [16,17]. Class 1 recalls are the most serious type of recall since they may involve serious injury to or death of the patient [16].

The availability of PMS studies on adverse events and malfunctions for PTCA catheters in patients with CAD in the published medical literature is unknown. In addition, the various methods adopted to monitor the safety of this device following its implementation in clinical settings remain elusive. By performing a systematic review of the literature to identify safety problems associated with the device, we may be able to determine whether the published medical literature is a useful source of information to estimate the safety of PTCA catheters. If we find useful information, then this approach could be adapted to monitor the safety of other devices.

\section{Objective}

The primary research objective is to review systematically the medical and grey literature, published between 2007 and 2012, for post-marketing surveillance studies on the frequency of incidents and malfunctions associated with the use of PTCA catheters in clinical practice among patients with CAD.

\section{Methods}

\section{Literature search strategy}

We identified the published literature by searching the following bibliographic databases: MEDLINE (from 1946) with in-process records and daily updates via Ovid, EMBASE (from 1980) via Ovid, the Cochrane Central Register of Controlled Trials (2012, Issue 1) via Ovid and PubMed. The search strategy consisted of both controlled 
vocabulary, such as the National Library of Medicine's MeSH (medical subject headings), and keywords. The main search concepts were percutaneous transluminal coronary angioplasty, heart catheterization and cutting or scoring catheters combined with equipment safety and failure, adverse events, post-marketing surveillance, medical device recalls and withdrawals. The search strategy is given in Additional file 1: Table S1. We limited the search to English and French language documents published between 1 January 2007 and 16 July 2012 to reflect the potential impact of the reclassification of PTCA catheters from a class III to class II risk level by the FDA on patient safety. We identified grey literature (literature that is not commercially published) by searching relevant sections of the Grey Matters checklist [18].

\section{Selection criteria}

The selection criteria include RCTs and non-randomized studies, such as cohort and case-control studies, case series and reports, that presented incidents, adverse events, procedure complications or device malfunctions related to the use of PTCA catheters among adult and paediatric populations. Two reviewers (JP and $\mathrm{KC}$ ) selected the final articles for inclusion based on an examination of the full publications. Any disagreements between the reviewers were discussed until a consensus was reached. For our systematic review, incidents were defined as events or circumstances that could have or did lead to unintended and/or unnecessary harm to a person, and/or a complaint, loss or damage; and adverse events were defined as an unintended injury caused by medical management rather than by a disease process [19].

Conference abstracts, letters and editorials were excluded. In addition, studies conducted to demonstrate the effectiveness and safety of the devices for market approval were not included in this systematic review.

\section{Article selection}

Two individuals (JP, KC) independently reviewed the titles and abstracts of search results and selected articles for inclusion based on the eligibility criteria. Rather than resolving selection differences, all those selected by at least one reviewer were retrieved since ultimate judgment about inclusion must often be reserved until the full text is examined. If more than one publication described a single study and each presented the same data, the most recent was included. Both reviewers compared findings and resolved differences through discussion, after which one study for each eligible instance was captured for further analysis.

\section{Data extraction}

One reviewer (JP) conducted the data abstraction for all included studies using pre-specified extraction forms, and another reviewer $(\mathrm{KC})$ verified the accuracy of the data extracted from all included reports. Any disagreements between the reviewers were discussed until a consensus was reached.

\section{Quality assessment of included studies}

Two reviewers (JP and KC) critically appraised independently the internal validity of the included studies using checklist tools for RCTs and cohort and case-control studies available on the Scottish Intercollegiate Guidelines Network website. Separate methodology checklists by study design were used to assess the internal validity and overall assessment of the study, including the generalizability. Each tool addresses how well a study meets the different components of the study design that may impact the study findings and conclusions [20].

\section{Data analysis and synthesis}

A formal meta-analysis was not performed since the aim of this systematic review is to identify and present the literature on adverse events and device malfunctions for PTCA catheters reported in PMS studies, rather than to test a hypothesis. Instead, the study design, medical device, patient population, health-care setting, interventions, adverse events and device malfunctions measured in each selected study were reviewed and described individually.

\section{Results}

\section{Quantity of research available}

The literature search identified 5,942 citations. Of these, the full text of 144 potentially relevant articles was retrieved for further review. For this review, 11 studies were selected for inclusion. Studies were excluded if they included inappropriate study participants, measured an inappropriate device, such as guidewires, guiding catheters and bare-metal or drug-eluting stents, did not specify the devices employed during the percuntaneous coronary intervention (PCI) (also known as coronary angioplasty), measured irrelevant outcomes, or limited the findings to long-term clinical outcomes. The Preferred Reporting Items for Systematic Reviews and Meta-Analyses (PRISMA) flowchart in Figure 1 outlines the study selection process.

\section{Study characteristics}

Four studies were conducted in Germany [21-24], two in Italy [25,26], and one each in Israel [27], Taiwan [28], the US [29] and Japan [30]. One study was performed in Italy and the UK [31]. Table 1 is a complete list of study characteristics. 


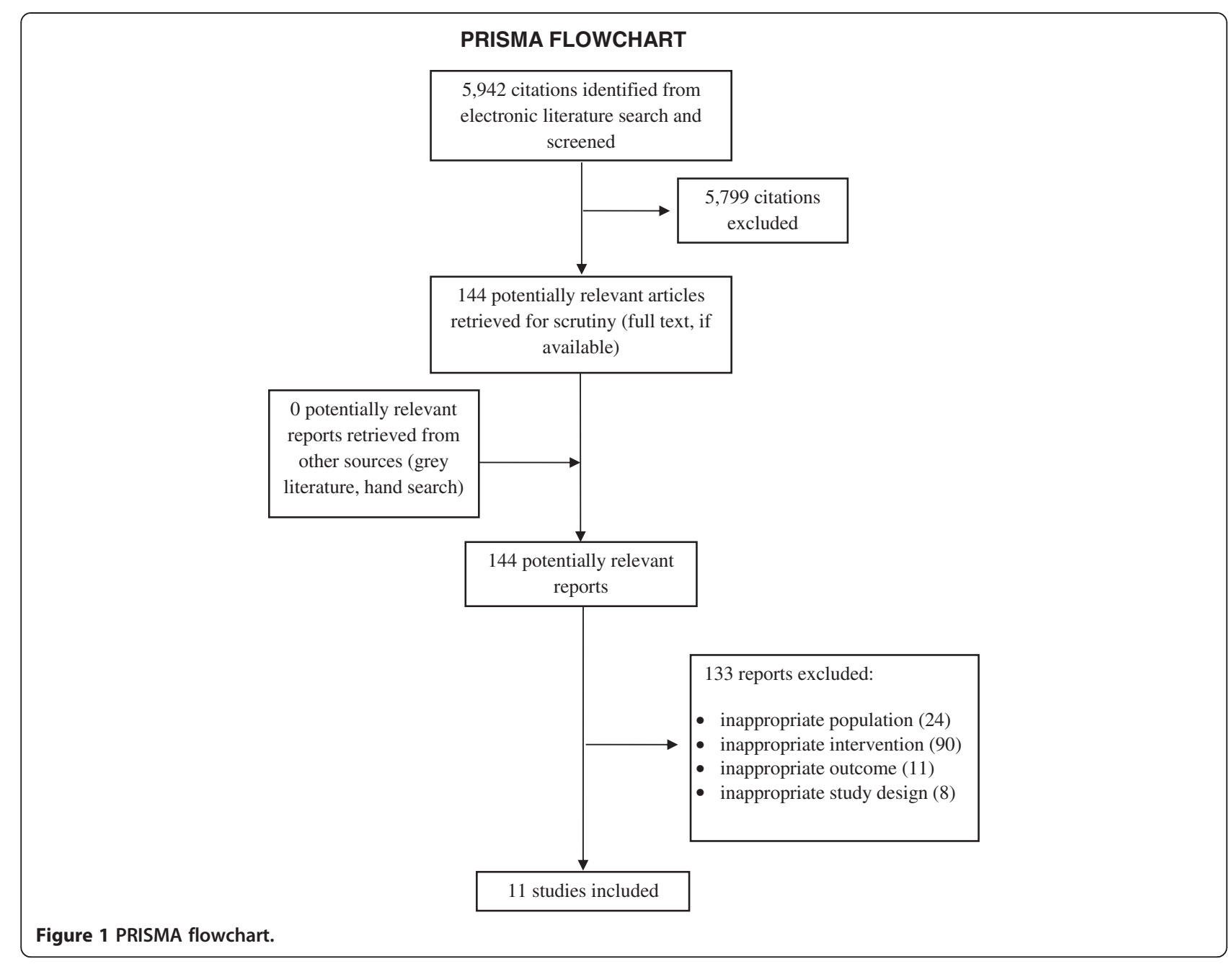

\section{Study design}

Three studies were non-blinded randomized trials $[22,23,25]$. A single-arm prospective cohort study design was used in three studies $[21,28,29]$ and one study was a three-arm prospective cohort in design [24]. Three studies were retrospective cases series [31], one was a single-arm retrospective cohort [30], one a three-arm retrospective cohort [26] and one a case-control study [27]. Four studies were multi-centred [21-23,29]. The two- or three-armed studies assessed the comparative effectiveness of PTCA catheters with comparable devices or procedures. The one-armed studies aimed to measure the rates of success or complications for the patient with the use of the device.

\section{Patient population}

Two studies included populations with coronary perforations $[28,31]$ and two studies included patients with restenosis $[22,26]$. Patients with coronary total obstruction lesions were selected in another two studies [22,26], and patients with stable or unstable angina were included in two studies [23,25]. Two studies encompassed patients with single- or multi-vessel CAD [24,29], and the morbidities of a patient population undergoing PCI was not available in one study [27]. Sample sizes ranged from 21 [28] to 996 [24].

\section{Intervention and comparators}

In most studies, patients were treated with aspirin $[21,22,25,29,31]$, thienopyridine [31], clopidogrel [21,22, $25,29]$, heparin [22,28,31] or dual antiplatelet therapy and procedural anticoagulation [29]. Guidewires and guiding catheters were used in four studies as part of the procedure $[21,27,28,30]$. Two studies incorporated stent implantation in the study population [28,31], and one study used intracoronary compliant, non-compliant or cutting balloons [31]. A balloon's compliance refers to its expandability: compliant balloons are flexible and noncompliant balloons are considered to be inflexible [32]. Balloon catheters in the studies were the Stingray balloon catheter [21], Ryujin ${ }^{\oplus}$ [30], Lacross ${ }^{\oplus}$ [30], Maverick ${ }^{\oplus}$ [30], PEGASO $^{\mathrm{TM}}$ by SORIN Biomedica [23] and balloon 
Table 1 Study characteristics

\begin{tabular}{lll}
\hline $\begin{array}{l}\text { First author, year } \\
\text { and country of } \\
\text { publication }\end{array}$ & $\begin{array}{l}\text { Study design, } \\
\text { length of study, } \\
\text { source of } \\
\text { funding }\end{array}$ & Population \\
\hline Al-Lamee, 2011 [31] & $\begin{array}{l}\text { Retrospective case } \\
\text { series }\end{array}$ & $\begin{array}{l}56 \text { patients who } \\
\text { underwent PCl and } \\
\text { had grade III coronary } \\
\text { perforation }\end{array}$ \\
\hline Italy and UK & $\begin{array}{l}\text { May 1993 to } \\
\text { December 2009 }\end{array}$ &
\end{tabular}

Source of funding:

NR
Interventions and comparators

Outcomes: adverse events

and device malfunctions

associated with balloon angioplasty

Perforation caused by intracoronary compliant balloon: 15/56; 26.8\%

All patients received aspirin and a loading dose of thienopyridine prior to procedure. All patients then received intravenous heparin with an initial 100-U/kg bolus followed by additional heparin until targeted clotting time $>250 \mathrm{~s}$ was achieved.

$\mathrm{PCl}$ was conducted with predilation and stent implantation using standard techniques via the femoral artery. Following the procedure, all patients received aspirin or dual antiplatelet therapy with aspirin and thienopyridine therapy if patient received intracoronary stents.

\begin{tabular}{lll}
\hline Werner, $2011[21]$ & $\begin{array}{l}\text { Single-arm } \\
\text { prospective } \\
\text { cohort multi- } \\
\text { centre study }\end{array}$ & $\begin{array}{l}42 \text { patients with } \\
\text { coronary CTOs }\end{array}$ \\
&
\end{tabular}

Germany July 2008 to June

2009

Source of funding: NR

BridgePoint devices).

\author{
Perforation caused by \\ intracoronary non-compliant \\ balloon: 13/56; 23.2\% \\ Perforation caused by \\ intracoronary cutting balloon: \\ 4/56; $7.1 \%$
}

$\begin{array}{ll}\text { All patients were recanalized on } & \text { In-hospital complications in } \\ \text { aspirin }(100 \mathrm{mg}) \text { and received } & \text { patients with BridgePoint } \\ \text { clopidogrel }(75 \mathrm{mg}) \text { with a } & \text { devices: }\end{array}$

loading dose of $600 \mathrm{mg}$ for 12 months from the start of procedure.

Lesions were crossed with

guidewires (Stingray ${ }^{\oplus}$,

BridgePoint devices) supported

by an exchange catheter

(CrossBoss $^{\text {TM }}$ Catheter, BridgePoint

devices) or a low profile over-

the-wire catheter (Stingray ${ }^{\oplus}$,

Balloon dilation was conducted with increasing sizes, and a stent of an appropriate size was implanted. A balloon-to-artery ratio of 1.1 with inflation pressures of 12 to $16 \mathrm{~atm}$ was used.

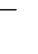


Table 1 Study characteristics (Continued)

\begin{tabular}{|c|c|c|c|c|}
\hline & & & $\begin{array}{l}\text { Balloon length, number of } \\
\text { catheters and number of } \\
\text { inflations used during procedures } \\
\text { were up to investigators' } \\
\text { discretion. }\end{array}$ & \\
\hline Cortese, 2010 [25] & $\begin{array}{l}\text { Single-centre } \\
\text { randomized trial }\end{array}$ & $\begin{array}{l}60 \text { adult patients with } \\
\text { stable or unstable angina } \\
\text { and clinical indication for } \\
\mathrm{PCl} \text { of at least one small } \\
\text { coronary artery } \\
(\leq 2.75 \mathrm{~mm})\end{array}$ & $\begin{array}{l}\text { All patients received aspirin } \\
\text { (either } 100 \text { mg/day for at least } \\
\text { three days prior or pre-PCl } 300 \\
\text { mg intravenous bolus), and } \\
\text { clopidogrel ( } 300 \text { or } 600 \mathrm{mg} \text { as a } \\
\text { loading dose, followed by } 75 \mathrm{mg} \\
\text { daily). }\end{array}$ & Procedural success: \\
\hline \multirow[t]{5}{*}{ Italy } & $\begin{array}{l}\text { Two investigators } \\
\text { were blinded to } \\
\text { patient treatment } \\
\text { allocation }\end{array}$ & & $\begin{array}{l}28 \text { patients were randomized to } \\
\text { Dior paclitaxel-coated balloon } \\
\text { (PCB) (Eurocor, Bonn, Germany) }\end{array}$ & PCB: $27 / 28 ; 96.4 \%$ \\
\hline & \multirow{2}{*}{$\begin{array}{l}\text { CTR number } \\
\text { (EudraCT code): } \\
\text { 2009-012268-15 }\end{array}$} & & \multirow{4}{*}{$\begin{array}{l}29 \text { patients were randomized to } \\
\text { Taxus }^{T M} L^{\prime} \text { iberté } e^{T M} \text { DES }\end{array}$} & Taxus stent: $29 / 29 ; 100 \%$ \\
\hline & & & & \multirow[t]{3}{*}{$P=0.30$} \\
\hline & $\begin{array}{l}\text { August } 2007 \text { to } \\
\text { August } 2008\end{array}$ & & & \\
\hline & $\begin{array}{l}\text { Source of funding: } \\
\text { NR }\end{array}$ & & & \\
\hline Shimony, 2009 [27] & $\begin{array}{l}\text { Case-control } \\
\text { study }\end{array}$ & \multirow{16}{*}{$\begin{array}{l}228 \text { patients who } \\
\text { underwent } \mathrm{PCI} \text { (including } \\
\text { wires, balloons and } \\
\text { stents) }\end{array}$} & Group 1: 57 patients with CP & Equipment causing CP: \\
\hline \multirow[t]{15}{*}{ Israel } & $\begin{array}{l}\text { January } 2001 \text { to } \\
\text { December } 2008\end{array}$ & & \multirow[t]{15}{*}{ Group 2: 171 patients without CP } & Wire: 30/57; 53\% \\
\hline & \multirow{14}{*}{$\begin{array}{l}\text { Source of funding: } \\
\text { NR }\end{array}$} & & & Balloon: 15/57; 26\% \\
\hline & & & & Stents: $12 / 57 ; 21 \%$ \\
\hline & & & & $\begin{array}{l}\text { Equipment causing Grade I } \\
\text { CP (Ellis classification): }\end{array}$ \\
\hline & & & & Wire: $3 / 7$ \\
\hline & & & & Balloon: 2/7 \\
\hline & & & & Stents: $2 / 7$ \\
\hline & & & & $\begin{array}{l}\text { Equipment causing Grade ॥ } \\
\text { CP (Ellis classification): }\end{array}$ \\
\hline & & & & Wire: $18 / 30$ \\
\hline & & & & Balloon: 7/30 \\
\hline & & & & Stents: $5 / 30$ \\
\hline & & & & $\begin{array}{l}\text { Equipment causing Grade II } \\
\text { CP (Ellis classification): }\end{array}$ \\
\hline & & & & Wire: 9/20 \\
\hline & & & & Balloon: 6/20 \\
\hline & & & & Stents: $5 / 50$ \\
\hline $\begin{array}{l}\text { Unverdorben, } \\
2009 \text { [22] }\end{array}$ & $\begin{array}{l}\text { Randomized } \\
\text { non-blinded } \\
\text { multicentre trial }\end{array}$ & $\begin{array}{l}131 \text { patients for the } \\
\text { treatment of coronary in- } \\
\text { stent restenosis }\end{array}$ & $\begin{array}{l}\text { All patients were treated with } \\
250 \text { mg of aspirin intravenously, } \\
\text { heparin as an initial bolus of } 70 \\
\text { to } 200 \mathrm{U} / \mathrm{kg} \text { body weight } \\
\text { adjusted according to the } \\
\text { activated clotting time with a } \\
\text { target of } 200 \text { to } 250 \text { seconds. } \\
\text { One day before the procedure, a } \\
\text { loading dose of } 300 \mathrm{mg} \text { of } \\
\text { clopidogrel was administered or } \\
600 \text { mg before the intervention. } \\
\text { All patients were assessed based } \\
\text { on angiographic inclusion and } \\
\text { exclusion criteria. }\end{array}$ & $\begin{array}{l}\text { Success rate with crossing } \\
\text { the lesion: }\end{array}$ \\
\hline
\end{tabular}


Table 1 Study characteristics (Continued)

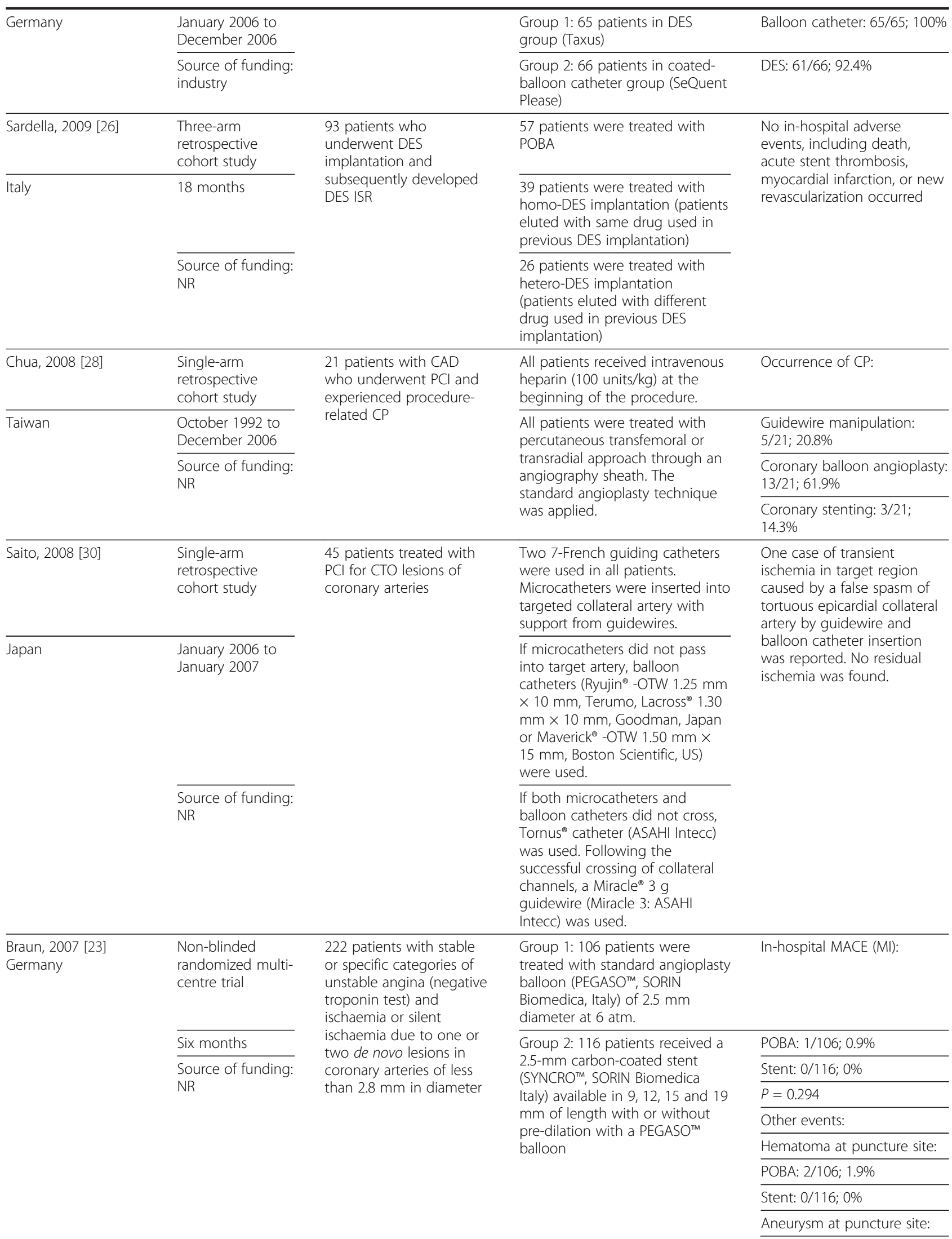




\begin{tabular}{|c|c|c|c|c|}
\hline & & & & POBA: 0/106; 0\% \\
\hline & & & & Stent: $1 / 116 ; 0.01 \%$ \\
\hline & & & & Pericardial effusion: \\
\hline & & & & POBA: 0/106; 0\% \\
\hline & & & & Stent: $1 / 116 ; 0.01 \%$ \\
\hline & & & & Contrast reaction: \\
\hline & & & & POBA: $2 / 106 ; 1.9 \%$ \\
\hline & & & & Stent: $0 / 116 ; 0 \%$ \\
\hline & & & & $P=0.347$ \\
\hline $\begin{array}{l}\text { Völzke, } 2007 \text { [24] } \\
\text { Germany }\end{array}$ & $\begin{array}{l}\text { Three-arm } \\
\text { prospective } \\
\text { cohort }\end{array}$ & 996 patients with CAD & $\begin{array}{l}\text { CABG Group: } 240 \text { patients were } \\
\text { administered heparin in a dose } \\
\text { of } 2 \text { to } 3 \mathrm{mg} / \mathrm{kg} \text { before surgery. } \\
\text { Aspirin and coumarin were } \\
\text { administered following } \\
\text { discharge, as necessary }\end{array}$ & Mortality: \\
\hline & $\begin{array}{l}\text { Approximately } 8.5 \\
\text { years }\end{array}$ & & $\begin{array}{l}\text { PTCA Group: } 478 \text { patients } \\
\text { received heparin }(10,000 \mathrm{IU}) \text { prior } \\
\text { to the procedure. All patients } \\
\text { received aspirin and coumarin } \\
\text { upon discharge as necessary. }\end{array}$ & PTCA: 95/478; 19.9\% \\
\hline & Source of funding: & & CABG Group: 278 patients & CS: 45/278; $16.2 \%$ \\
\hline & government & & received heparin $(10,000 \mathrm{IU})$. & CABG: 53/240; 22.1\% \\
\hline & & & unsuccessful PTCA or & MACE: \\
\hline & & & $\begin{array}{l}\text { experienced acute complications } \\
\text { during the procedure }\end{array}$ & PTCA: $317 / 478 ; 66.3 \%$ \\
\hline & & & Subsequently, they received & CS: $138 / 278 ; 49.6 \%$ \\
\hline & & & stent implantation. Patients & CABG: $80 / 240 ; 33.3 \%$ \\
\hline & & & and ticlopidine (250 mg b.d.). All & Incident MI: \\
\hline & & & patients received aspirin and & PTCA: $31 / 478 ; 6.5 \%$ \\
\hline & & & the first 28 days. & CS: $22 / 278 ; 8.0 \%$ \\
\hline & & & & CABG: $18 / 240 ; 7.5 \%$ \\
\hline & & & & Incident percutaneous TVR \\
\hline & & & & PTCA: $210 / 478 ; 44.1 \%$ \\
\hline & & & & CS: $83 / 278 ; 30.2 \%$ \\
\hline & & & & CABG: $26 / 240 ; 10.9 \%$ \\
\hline & & & & Incident operative TVR: \\
\hline & & & & PTCA: 76/478; 16.0\% \\
\hline & & & & CS: $35 / 278 ; 12.7 \%$ \\
\hline & & & & CABG: $1 / 240 ; 0.4 \%$ \\
\hline
\end{tabular}

$C A D$ coronary artery disease, $C P$ coronary artery perforation, $C S$ coronary stent, $C T O$ coronary total occlusion, CTR clinical trial registration, $D E S$ drug eluting stent, ISR in-stent restenosis, MACE major adverse cardiac event, $M I$ myocardial infarction, NR not reported, NSTEMI non-ST elevation myocardial infarction, PCI percutaneous coronary intervention, POBA plain old balloon angioplasty, PTCA percutaneous transluminal coronary angioplasty, TVR target vessel revascularization.

catheters by Medtronic Cardiovascular [29]. The use of paclitaxel-coated balloon catheters mad by Eurocar [29] and coated-balloon catheters by SeQuent Please [22] were also studied. Two studies compared the effectiveness and safety of drug-coated balloon catheters with a drug eluting stent (DES) [22,25], two studies compared the outcomes in patients who were treated with standard balloon angioplasty versus those with DES implantation [23,26]. One prospective study compared the long-term prognosis following the PTCA procedure with coronary stenting and
CABG [24]. Details of the interventions were not available in one study [27].

\section{Quality assessment}

A quality assessment of single-arm studies was not performed since these study designs were descriptive, provided limited information and did not test any hypotheses. The methodological quality of six studies was reviewed [22-27]. In the case-control study, the interventional cardiologist, who determined the severity of 
coronary perforation among the patients, was blinded to the clinical outcomes to reduce the risk of information bias [27]. Although the authors conducted a multiple logistic regression analysis to identify the predictors for coronary perforation, the selection of variables was not discussed, and it was uncertain if potential confounders were adjusted for in the study [27]. An assessment of the retrospective cohort study found that it was unclear if the investigators were blinded to the outcomes or if potential confounders were considered in the study design and analysis [26]. Moreover, the authors did acknowledge that failure to randomize the patient populations may have influenced the study findings [26]. Three randomized trials were not blinded, which increases the risk of information bias for the study outcomes [22,23,25]. In one trial, the two study investigators were blinded to the patient treatment allocation [25]. Two studies did not discuss the percentage or number of patients who dropped out or were lost to follow-up before the study ended $[22,23]$, but three out of 57 patients were lost to follow-up in the PICCOLETO study [25]. In addition, intention-totreat (ITT) analysis was mentioned in two trials, but it was not described [22,25]. One study did not indicate if the analyses were done on an ITT basis, so it is difficult to determine if the participants remained randomized throughout the study [23]. Two trials had multiple study centres where it was not possible to determine if the outcomes were comparable across all sites [22,23]. In one prospective cohort study, several baseline demographic and clinical characteristics differed among the patient groups, which may be associated with the measured outcomes [24]. For example, patients who received CABG surgery were older, were more likely to be male or diabetic, have a previous history of MI or increased disease severity versus patients with PTCA [24]. Patients with coronary stents also were more likely to have a positive MI history, a three-vessel $\mathrm{CAD}$, and left anterior descending or stenosis greater than $50 \%$ in the right coronary artery compared with patients with PTCA [24].

\section{Data analysis and synthesis Adverse events}

No in-hospital adverse events, such as death, acute stent thrombosis, myocardial infarction or revascularization, were reported to have occurred due to a complication of balloon angioplasty [26]. One case of in-hospital myocardial infarction was reported in one study for a patient with angina, who was treated with a standard angioplasty balloon $(1 / 106 ; 0.9 \%)$ [23]. Furthermore, two patients suffered from hematoma at a puncture site $(2 / 106 ; 1.9 \%)$, and from contrast reaction $(2 / 106 ; 1.9 \%)$. In the same study, no inhospital major acute coronary events were found with patients who were treated with carbon-coated stents $(0 / 116$; $0 \%)$. One patient, however, experienced an aneurysm at a puncture site with the use of a stent [23]. In a single-arm study, the frequency of coronary perforation was the highest with the application of coronary balloon angioplasty $(13 / 21 ; 61.9 \%)$ compared with guidewire manipulation $(5 / 21 ; 20.8 \%)$ and coronary stenting $(3 / 21 ; 14.3 \%)$ [28]. Coronary perforation is a rare but sometimes fatal complication associated with PCI [33]. Another singlearm study, which included only patients with a coronary perforation, found that there were more patients with a perforation with the use of intracoronary compliant balloon catheters $(15 / 56 ; 26.8 \%)$ versus intracoronary noncompliant balloon catheters $(13 / 56 ; 23.2 \%)$ and cutting balloons (4/56; 7.1\%); however, there was no data on the total number of patients using each type of balloon [28]. Among patients who experienced a grade III coronary perforation, Shimony et al. found that the use of wires (30/57; $53 \%$ ) was associated with the greatest frequency of coronary perforation compared with balloon catheters (15/57; $26 \%)$ and stents $(12 / 57 ; 21 \%)$ [27]. This study only included patients with perforations, therefore, no data on the number of patients treated with each device was recorded. Long-term mortality was 22.1\% (53/240) among patients who underwent CABG versus those with PTCA (19.9\%; 95/478) and those with coronary stents (16.2\%; 45/ 278) [24]. A greater proportion of patients with PTCA experienced major adverse cardiac events (66.3\%; 317/ $478)$ versus those with coronary stents $(49.6 \%$; 138/278), followed by CABG (33.3\%; 80/240) [24]. Conclusions regarding differences in rates in this study are impossible because of a lack of randomization.

\section{Procedure complications}

There were no procedure complications associated with balloon or balloon-coated catheters reported in two studies [22,29]. Procedural success occurred in 96.4\% (27/28) of cases with paclitaxel-coated balloon catheters versus 100\% (29/29) with Taxus stents [25]. One study reported occurrences of failure with the use of Stringray balloons. For instance, failure to advance into the proper position $(2 / 14 ; 14.3 \%)$, to advance after a re-entry attempt $(3 / 10$; $30 \%)$ and a re-entry puncture as a result of loss of distal contrast filling $(2 / 10 ; 20 \%)$ were reported [21].

\section{Device malfunctions}

One study indicated that there were no balloon ruptures or failure of delivery with the application of a $1.25-\mathrm{mm}$ diameter angioplasty balloon among patients with CAD [29]. Occurrences of device malfunctions were not mentioned in the remaining studies.

\section{Discussion}

\section{Summary of evidence}

Our systematic review included 11 studies that reported in-hospital adverse events, procedure complications and 
device malfunctions with the use of PTCA catheters in patients with CAD. In-hospital adverse events reported were individual cases of myocardial infarction and hematoma. In studies of patients with coronary perforation, more patients with balloon angioplasty were identified compared with patients who required stenting; however, these studies neglected to evaluate the at-risk population. As more patients undergo angioplasty than stenting, then the comparative risk is uncertain. In these studies $[27,28]$, there were conflicting results regarding balloon angioplasty and guidewires. Since the interventions were not described in the studies, and study design and sample differed, it was difficult to determine the discrepancies in the findings between the studies. Procedure complications and device malfunctions were reported rarely and when they were they occurred infrequently. One review found that balloon-only PTCA was associated with a greater risk of angiographic restenosis versus bare-metal and drug-eluting stents [34]. Longterm adverse events reported in one study included mortality and MACE [24].

Our study highlights that a systematic review of the published and grey literature as a method to identify potential safety issues or ruptures associated with the use of PTCA catheters in patients with CAD is inadequate compared with the number of adverse reports submitted to the FDA in 2011 (1,942 adverse events in 2011). In most studies, the objectives were not to monitor the long-term safety aspects on the use of PTCA catheters in clinical practice. For instance, many studies ranged from 6 to 18 months in length, and their study populations were less than 250 patients. Even for short-term studies, the reporting of procedure- and device-related adverse events was inadequate. For example, several studies did not identify a denominator, so a hazard or risk ratio could not be determined. As the main objective of most selected studies was not to determine the incidents, adverse events or malfunctions associated with the use of PTCA catheters, it is uncertain that contacting the principal investigators of the published studies would have yielded additional insights with regards to their safety. Furthermore, there was no single classification system for complications, making it difficult to compare or aggregate adverse event types and risk across studies. Although the majority of the adverse event reports associated with the use of PTCA catheters submitted to the FDA were related to material rupture (data not reported), none of the selected studies reported any device malfunction when used in their clinical setting. Furthermore, the patient outcomes for 1,662 adverse event reports submitted to the FDA remained unknown. This lack of information precludes us from a comparison analysis between these outcomes and patient outcomes reported in the selected studies.
Another limitation is the lack of standard reporting of device brands and models. PTCA catheter brands and models were reported in only four studies $[21,23,29,30]$. Medical devices do not have an assigned unique identifier. Consequently, it is impossible to identify the specific device used in a patient if an adverse event occurs after the fact. Furthermore, none of the retrospective studies described the registries or existing surveillance programs in their institutions. Details of the structures used for data collection, intended use of the data and subsequent approaches to improve patient care would offer clarification on PMS in clinical practice. Important considerations in the development of research methodologies to identify the risk of adverse events and device malfunctions include product lifecycle, the learning curve of the device operator and the use of a device external to the original indication [35].

RCTs are considered to be the gold standard in the medical literature. Numerous disadvantages, however, exist with the sole use of clinical trials to assess the safety and effectiveness of medical devices. They are as follows: inadequate sample size to detect rare adverse events, short follow-up period, reduced generalizability of findings due to strict exclusion criteria, difficulties with maintaining blinding and allocation concealment, and high costs associated with designing many clinical trials for technologies that are evolving rapidly [36]. Normand et al. proposed a framework that combines pre-market and post-market data to measure the performance of medical devices [36]. To illustrate the proposed methods, a Bayesian hierarchical method was employed to combine clinical scores and outcomes from three studies using a RCT and observational designs on hip arthroplasty. The authors concluded that this method allows the performance data of medical devices to be monitored throughout the product lifecycle, increases transparency with explicit assumptions and is indicative of existing evidence gaps [36].

\section{Limitations}

Our literature search strategy was limited to the published and grey literature of full-text reports available in the past five years, to determine the impact of the reclassification of PTCA catheters from a class III to class II risk level by the FDA in 2011 and to identify studies relevant to current clinical practice. Studies were also restricted to English and French publications due to limited resources and time restrictions. Although Morrison et al. found no systematic bias when English-language restrictions were imposed in systematic reviews, the authors of the current review acknowledge that some bias may still exist by imposing language restrictions in the literature search strategy as further research is required in this area [37]. It is unlikely that we would have found a sufficient number of studies in other languages to 
change our conclusion about the gap between the number of reports in the published medical and grey literature and the number of reports from the FDA as the gap is significant. In addition, the inclusion criteria were defined by the published and grey literature. According to the results of the systematic review, it is a challenge to estimate accurately the extent of adverse events and device malfunctions associated with the use of PTCA in patients with CAD based solely on the available published and grey literature. As our primary study objective was to review the PMS studies in the medical and grey literature published between 2007 and 2012, we did not contact the authors of the included studies to obtain additional details. The limited information available in some of these studies is indicative of the inadequate reporting of PMS associated with the use of PTCA catheters in patients with CAD in the medical and grey literature. Doshi et al. suggested that complete and anonymized clinical study reports would provide supplemental evidence that is not available in publications, partly due to word limits imposed by biomedical journals [38]. For instance, one published trial on oseltamivir reported no adverse events, while the clinical study report listed three that may have been associated with its use [38]. On the other hand, manufacturers are not required to conduct a clinical trial to demonstrate the safety and efficacy of a medical device for pre-market approval.

\section{Directions for future research}

Medical devices that pose an increased risk of harm in patients could be an important indicator for the discontinuation of their use in patients. Our systematic review, however, illustrates that the volume and quality of PMS studies associated with the PTCA catheters in patients with $C A D$ are low in the published and grey literature, and are not useful sources of information for decisions on safety. The validity and feasibility of other methods, such as the use of both published and unpublished data, that can inform the risk of the use of a medical device warrant further exploration.

Since clinical trials are not required for medical devices for pre-market approval, databases and surveillance systems for reporting adverse events associated with medical devices may provide some insight that is unavailable in published studies. Passive surveillance systems, such as the MAUDE database [39], are considered to underreport adverse events. Reasons for underreporting include the inability to link an adverse event to a specific device, lack of awareness of the reporting systems, a lack of an obligation to report adverse events and concerns with liability issues [36]. Another concern with surveillance systems is the challenge in accurately detecting the cause of the adverse events. Further investigations are required to improve current surveillance systems. The FDA launched MedSun, a Medical Product Safety Network, in 2002. To date, trained representatives from over 350 health-care facilities, report adverse events to MedSun that occurred in their facility resulting from the use of a medical device [40]. One challenge that remains is capturing the number of devices used in practice, which would give a better understanding of the rate of related adverse events [41]. The comprehensiveness of the database and its impact in risk management merit further investigation.

New initiatives, such as the Medical Device Epidemiology Network, spearheaded by the FDA Center for Devices and Radiologic Health, aim to develop and advance research methods to improve the accuracy and volume of evidence on the safety and effectiveness of medical devices through collaborations with academic institutions. At the time of writing this review, the network was not fully operational [42], so its impact both on PMS and in clinical practice cannot be assessed yet. Future studies may examine innovative statistical methods to combine information from diverse data sources and study designs to assess the safety and effectiveness of medical devices, such as PTCA catheters, accurately.

\section{Conclusions}

Our systematic review included 11 studies on PMS of PTCA catheters in patients with CAD. The study designs included single- and multiple-arm prospective and retrospective studies, non-blinded RCTs and case-control studies. Their internal validity was generally low. The reported in-hospital and long-term adverse events involved coronary perforations, MACE and mortality. There were limited reports of adverse events common in clinical practice such as procedure failures, distal vessel occlusion due to embolization and puncture site complications. One study did not observe any device malfunctions, and the procedural complications reported in two studies did not appear to impact patient care severely. Given the volume of adverse events reported to the FDA since 2008, it is unlikely that the published and grey literature represent the full spectrum of device malfunctions and adverse events caused by the use of PTCA catheters. Future studies may explore the strengths and limitations of PMS databases administered by regulatory authorities. Innovative study designs and statistical methods to measure the safety and effectiveness of medical devices require further exploration.

\section{Additional file}

Additional file 1: Table S1. Literature search strategy.

\section{Abbreviations}

CAD: Coronary artery disease; CP: Coronary artery perforation; CS: Coronary stent; CTO: Coronary total occlusion; CTR: Clinical trial registration; DES: Drug eluting stent; FDA: US Food and Drug Administration; ISR: In-stent restenosis; ITT: Intention-to-treat; MACE: Major adverse cardiac event; MeSH: Medical 
subject headings; MI: Myocardial infarction; NR: Not reported; NSTEMI: NonST elevation myocardial infarction; PCl: Percutaneous coronary intervention; PMA: Pre-market approval; PMS: Post-marketing surveillance; POBA: Plain old balloon angioplasty; PRISMA: Preferred reporting items for systematic reviews and meta-analyses; PTCA: Percutaneous transluminal coronary angioplasty; RCT: Randomized clinical trial; TVR: Target vessel revascularization.

\section{Competing interests}

The authors declare that they have no competing interests.

\section{Authors' contributions}

JP led the systematic review and preparation of the manuscript. AJF contributed to and reviewed the draft versions of the manuscript. KC participated in the systematic review and reviewed the draft versions of the manuscript. DR developed and ran the literature search and reviewed draft versions the manuscript. All authors read and approved the final manuscript.

\section{Acknowledgements}

This work has been completed in partial fulfilment of the requirements for Julie Polisena's PhD degree in Epidemiology at the University of Ottawa. Julie Polisena is funded by the University of Ottawa Admission Scholarship.

\section{Author details}

${ }^{1}$ Canadian Agency for Drugs and Technologies in Health, Ottawa, 600-865 Carling Ave K1S 5S8, Ontario, Canada. ${ }^{2}$ Department of Epidemiology and Community Medicine and Epidemiology, University of Ottawa, Ottawa, Ontario, Canada. ${ }^{3}$ Clinical Epidemiology Program, Ontario Hospital Research Institute, Ottawa, Ontario, Canada. ${ }^{4}$ Performance Management, The Ottawa Hospital, Ottawa, Ontario, Canada. ${ }^{5}$ Department of Medicine, Faculty of Medicine, University of Ottawa, Ottawa, Ontario, Canada. Institute for Clinical Evaluative Sciences, Ottawa, Ontario, Canada.

Received: 27 March 2013 Accepted: 27 September 2013 Published: 10 October 2013

\section{References}

1. Maisel WH: Medical device regulation: an introduction for the practicing physician. Ann Intern Med 2004, 140:296-302.

2. O'Keeffe K: The rise of medtech. MDDl: Med Device Diagn Ind 2011: [http:// www.mddionline.com/article/rise-medtech] (accessed 2 January 2012).

3. Feldman MD, Petersen AJ, Karliner LS, Tice JA: Who is responsible for evaluating the safety and effectiveness of medical devices? The role of independent technology assessment. J Gen Intern Med 2008, 23(Suppl 1):57-63.

4. Fraser AG, Daubert JC, Van de Werf F, Estes NA 3rd, Smith SC Jr, Krucoff MW, Vardas PE, Komajda M, participants: Clinical evaluation of cardiovascular devices: principles, problems, and proposals for European regulatory reform. Report of a policy conference of the European Society of Cardiology. Eur Heart J 2011, 32:1673-1686.

5. Taylor RS, Iglesias CP: Assessing the clinical and cost-effectiveness of medical devices and drugs: are they that different? Value Health 2009, 12:404-406.

6. Device approvals and clearances. [http://www.fda.gov/medicaldevices/ productsandmedicalprocedures/deviceapprovalsandclearances/default.htm] (accessed 4 July 2013).

7. Drummond M, Griffin A, Tarricone R: Economic evaluation for devices and drugs - same or different? Value Health 2009, 12:402-404.

8. Brown SL, Bright RA, Tavris DR: Medical device epidemiology and surveillance: patient safety is the bottom line. Expert Rev Med Devices 2004, 1:1-2.

9. Health Canada: Planning for our future: federal regulatory post-market surveillance strategy - 2007-2012. Ottawa: Health Canada; 2007.

10. Torrence ME: Data sources: use in the epidemiologic study of medical devices. Epidemiology 2002, 13(Suppl 3):S10-S14.

11. Dhruva SS, Bero LA, Redberg RF: Strength of study evidence examined by the FDA in premarket approval of cardiovascular devices. JAMA 2009, 302:2679-2685.

12. Mehran R, Leon MB, Feigal DA, et al: Post-market approval surveillance: a call for a more integrated and comprehensive approach. Circulation 2004, 109:3073-3077.
13. Rosamond W, Flegal K, Furie K, Go A, Greenlund K, Haase N, Hailpern SM, Ho M, Howard V, Kissela B, Kittner S, Lloyd-Jones D, McDermott M, Meigs J, Moy C, Nichol G, O'Donnell C, Roger V, Sorlie P, Steinberger J, Thom T, Wilson M, Hong Y, American Heart Association Statistics Committee and Stroke Statistic Subcommittee: Heart disease and stroke statistics - 2008 update: a report from the American Heart Association Statistics Committee and Stroke Statistics Subcommittee. Circulation 2007, 117:e25-e146.

14. Stanford Hospital \& Clinics: Percutaneous transluminal coronary angioplasty/stent placement. 2012: [http://stanfordhospital.org/healthLib/ greystone/heartCenter/heartProcedures/percutaneousTransluminalCoronary AngioplastyStentPlacement.html] (accessed 31 January 2012).

15. Clarimed: Overview of percutaneous transluminal coronary angioplasty catheters. 2012: [http://www.clarimed.com/medical-devices-categories/ percutaneous-transluminal-coronary-angioplasty-catheters/issues] (accessed 31 January 2012).

16. Hitt E: FDA recalls PTCA scoring balloon catheters. Medscape Med News 2010: [http://www.medscape.com/viewarticle/728354] (accessed 31 January 2012).

17. New FDA rule reclassifies PTCA catheters. Med Prod Outsourcing 2010: [http://www.mpo-mag.com/news/2010/10/13/new_fda_rule_reclassifies_ ptca_catheters] (accessed 7 February 2012).

18. Grey Matters. [http://www.cadth.ca/resources/grey-matters]

19. Committee of Experts on Management of Safety and Quality in Health Care (SP-SQS), Expert Group on Safety Medication Practices: Glossary of Terms Related to Patient and Medication Safety. Strasbourg: Council of Europe; 2005.

20. Scottish Intercollegiate Guidelines Network: SIGN 50: A Guideline Developer's Handbook. Edinburgh: SIGN; 2011. [http://www.sign.ac.uk/pdf/sign50.pdf] (accessed 28 June 2012).

21. Werner GS, Schofer J, Sievert H, Kugler C, Reifart NJ: Multicentre experience with the BridgePoint devices to facilitate recanalisation of chronic total coronary occlusions through controlled subintimal re-entry. Eurolntervention 2011, 7:192-200.

22. Unverdorben M, Vallbracht C, Cremers B, Heuer H, Hengstenberg C, Maikowski C, Werner GS, Antoni D, Kleber FX, Bocksch W, Leschke M, Ackermann H, Boxberger M, Speck U, Degenhardt R, Scheller B: Paclitaxelcoated balloon catheter versus paclitaxel-coated stent for the treatment of coronary in-stent restenosis. Circulation 2009, 119:2986-2994.

23. Braun P: Prospective randomized study of the restenotic process in small coronary arteries using a carbofilm coated stent in comparison with plain old balloon angioplasty: a multicenter study. Cathet Cardiovasc Interv 2007, 70:920-927.

24. Völzke H, Henzler J, Menzel D, Robinson DM, Hoffmann W, Vogelgesang D, John U, Motz W, Rettig R: Outcome after coronary artery bypass graft surgery, coronary angioplasty and stenting. Int J Cardiol 2007, 116:46-52.

25. Cortese B, Micheli A, Picchi A, Coppolaro A, Bandinelli L, Severi S, Limbruno $\mathrm{U}$ : Paclitaxel-coated balloon versus drug-eluting stent during $\mathrm{PCl}$ of small coronary vessels, a prospective randomised clinical trial. The PICCOLETO study. Heart 2010, 96:1291-1296.

26. Sardella G, Colantonio R, De Luca L, Conti G, Di Roma A, Mancone M, Canali E, Benedetti G, Fedele F: Comparison between balloon angioplasty and additional coronary stent implantation for the treatment of drug-eluting stent restenosis: 18-month clinical outcomes. J Cardiovasc Med (Hagerstown) 2009, 10:469-473.

27. Shimony A, Zahger D, Van Straten M, Shalev A, Gilutz H, llia R, Cafri C: Incidence, risk factors, management and outcomes of coronary artery perforation during percutaneous coronary intervention. Am J Cardiol 2009, 104:1674-1677.

28. Chua SK, Lee SH, Shyu KG, Hung HF, Lin SC, Cheng JJ: Incidence, management, and clinical outcomes of procedure-related coronary artery perforation: analysis of 13,888 coronary angioplasty procedures. Acta Cardiologica Sinica 2008, 24:80-85.

29. Kandzari DE, Zankar AA, Teirstein PS, Brilakis ES, Banerjee S, Price MJ, Stinis CT, Hudson PA, Dahle TG, Eng M, Brown R, Ferguson A, Addo TA, Popma JJ: Clinical outcomes following predilation with a novel $1.25-\mathrm{mm}$ diameter angioplasty catheter. Catheter Cardiovasc Interv 2011, 77:510-514.

30. Saito S: Different strategies of retrograde approach in coronary angioplasty for chronic total occlusion. Catheter Cardiovasc Interv 2008, 71:8-19.

31. Al-Lamee R, lelasi A, Latib A, Godino C, Ferraro M, Mussardo M, Arioli F, Carlino M, Montorfano M, Chieffo A, Colombo A: Incidence, predictors, management, immediate and long-term outcomes following grade III coronary perforation. JACC Cardiovasc Interv 2011, 4:87-95. 
32. Balloon for a dilation catheter and method for manufacturing a balloon. 2004: [http://www.patentstorm.us/patents/6696121/description.html] (accessed 28 March 2012).

33. Witzke CF, Martin-Herrero F, Clarke SC, Pomerantzev E, Palacios IF: The changing pattern of coronary perforation during percutaneous coronary intervention in the new device era. J Invasive Cardiol 2004, 16:257-301.

34. Biondi-Zoccai G, Moretti C, Abbate A, Sheiban I: Percutaneous coronary intervention for small vessel coronary artery disease. Cardiovasc Revasc Med 2010, 11:189-198.

35. Resnic FS, Normand SL: Postmarketing surveillance of medical devices filling in the gaps. N Engl J Med 2012, 366:875-877.

36. Normand SL, Marinac-Dabic D, Sedrakyan A, Kaczmarek R: Rethinking analytical strategies for surveillance of medical devices: the case of hip arthroplasty. Med Care 2010, 48:S58-S67.

37. Morrison A, Moulton K, Clark M, Polisena J, Fiander M, Mierzwinski-Urban M Mensinkai S, Clifford T, Hutton B: English-language restriction when conducting systematic review-based metaanalyses: systematic review of published studies. Ottawa: Canadian Agency for Drugs and Technologies in Health; 2009. [http:// www.cadth.ca/media/pdf/H0478_Language_Restriction_Systematic_Review_ Pub_Studies_e.pdf] (accessed 28 March 2012).

38. Doshi P, Jones M, Jefferson T: Rethinking credible evidence synthesis. BMJ 2012, 344:d7898.

39. US Food and Drug Administration: MAUDE - Manufacturer and User Facility Device Experience database; 1991. [http://www.accessdata.fda.gov/scripts/ cdrh/cfdocs/cfMAUDE/search.CFM] (accessed 9 July 2012).

40. About MedSun. [http://www.fda.gov/medicaldevices/safety/ medsunmedicalproductsafetynetwork/default.htm] (accessed 28 March 2012).

41. Rao SV, Califf RM, Kramer JM, Peterson ED, Gross TP, Pepine CJ, Williams DO, Donohoe D, Waksman R, Mehran R, Krucoff MW: Postmarket evaluation of breakthrough technologies. Am Heart J 2008, 156:201-208.

42. Medical Device Epidemiology Network (MDEpiNET). [http://www. accessdata.fda.gov/FDATrack/track-proj? program=cdrh\&id=CDRH-OSBMDEpiNet] (accessed 28 March 2012).

doi:10.1186/2046-4053-2-94

Cite this article as: Polisena et al:: Post-marketing surveillance in the published medical and grey literature for percutaneous transluminal coronary angioplasty catheters: a systematic review. Systematic Reviews 2013 2:94.

\section{Submit your next manuscript to BioMed Central and take full advantage of:}

- Convenient online submission

- Thorough peer review

- No space constraints or color figure charges

- Immediate publication on acceptance

- Inclusion in PubMed, CAS, Scopus and Google Scholar

- Research which is freely available for redistribution 